\title{
Intervención: cuidado del medio ambiente en la formación clúster de turismo alternativo, para el desarrollo regional
}

\section{Intervention: care of the environment in the alternative tourism cluster training, for regional development}

VALDEZ-GUERRERO, Raquel†*, ROBLES-ARIAS, Isela Margarita y REAL-MIRANDA, Ivana María

Tecnológico Nacional De México/ Instituto Tecnológico De La Paz, La Paz, Baja California Sur, Boulevard Forjadores De Baja California Sur 4720, CP: 23080, México.

ID $1^{\text {er }}$ Autor: Raquel, Valdez-Guerrero / ORC ID: 0000-0003-0972-0189, CVU CONACYT ID: 407004

ID 1 ${ }^{\mathrm{er}}$ Coautor: Isela Margarita, Robles-Arias / ORC ID: 0000-0001-5164-156X, CVU CONACYT ID: 404596

ID $2^{\mathrm{do}}$ Coautor: Ivana María, Real-Miranda / ORC ID: 0000-0003-1801-6572, CVU CONACYT ID: 957262

DOI: $10.35429 / J U S D .2020 .18 .6 .1 .9$

Recibido: 10 de Enero, 2020; Aceptado 30 de Junio, 2020

\section{Resumen}

Se abordan estrategias para desarrollo de un Plan de intervención ambiental en la formación del clúster de turismo alternativo para el desarrollo regional aplicado en El Triunfo, Baja California Sur que permita la reducción la pobreza a través de la generación del autoempleo en la región, aumentando la calidad de vida y sin comprometer el entorno natural. Como objetivo se incluye el identificar actividades y procesos estratégicos, que se integren a la puesta en marcha de empresas que en conjunto se conglomeren y formen un clúster de turismo alternativo. Para llevar cabo el mismo se utiliza la metodología de Intervención Modelo De Cambio Planeado en donde se recolecta información, se procesan datos, se analizan y se diseña el plan de intervención. Para efecto de esta investigación se han diseñado; un cuestionario para identificar el conocimiento y aplicación de las regulaciones de Ley de Equilibrio Ecológico y Protección al Medio Ambiente, aplicado a las empresas que conglomeradas conformaran el clúster y una matriz de observación para recopilar la información, para el procesamiento se han diseñado matrices comparativas con fin de identificar las oportunidades de mejora e incluirlas en el proceso de intervención.

Desarrollo regional, Cuidado del medio ambiente, Estrategias

\begin{abstract}
Strategies for the development of an Environmental Intervention Plan in the formation of the alternative tourism cluster for regional development applied in El Triunfo, Baja California Sur are addressed to allow poverty reduction through the generation of self-employment in the region, increasing the quality of life and without compromising the natural environment. The objective is to identify strategic activities and processes that are integrated into the start-up of companies that conglomerate together and form an alternative tourism cluster. To carry out the same, the Planned Change Model Intervention methodology is used, where information is collected, data is processed, the intervention plan is analyzed and designed. For the purpose of this investigation they have been designed; a questionnaire to identify the knowledge and application of the regulations of the Law of Ecological Balance and Protection of the Environment, applied to the companies that conglomerates make up the cluster and an observation matrix to collect the information, for the processing comparative matrices have been designed with in order to identify opportunities for improvement and include them in the intervention process.
\end{abstract}

Regional development, Care of the environment, Strategies

Citación: VALDEZ-GUERRERO, Raquel, ROBLES-ARIAS, Isela Margarita y REAL-MIRANDA, Ivana María. Intervención: cuidado del medio ambiente en la formación clúster de turismo alternativo, para el desarrollo regional. Revista del Desarrollo Urbano y Sustentable. 2020. 6-18:1-9.

\footnotetext{
*Correspondencia al autor (correo electrónico: raquelvaldezgro@hotmail.com)

$\dagger$ Investigador contribuyendo como primer autor
} 


\section{Introducción}

\section{Las intervenciones}

Una estrategia educativa como la que se aborda en el desarrollo organizacional para lograr un cambio planeado permite establecer metas, objetivos, y programas para que las organizaciones optimicen la posibilidad de obtener éxito en el desempeño de los proyectos diseñados para eficientar sus procesos, con la participación colaborativa de recurso humano que la integra. Entre los cambios que requieren las organizaciones se distinguen:

- Establecer metas, objetivos, planes de acción y estándares de desempeño.

- Actualizar la estructura organizacional y áreas de responsabilidad a las nuevas demandas de la organización.

- Diseñar e implantar nuevos sistemas y procedimientos de trabajo y tecnologías.

- Romper el estancamiento de la organización, eliminando procesos que no agregan valor.

- Reorientar las estrategias operativas, cuando no son apropiadas a las prioridades de crecimiento y mercado de la organización.

- La mejora de la salud financiera de la organización.

- Desarrollo de nuevos productos o posicionamiento en nuevos mercados o nichos.

(Audirac Camarena Carlos A., 2014) Para el logro de los cambios según el Desarrollo Organizacional se toman en consideración objetivos que deben surgir del diagnóstico de las situaciones que se deben modificar, pero existen objetivos básicos más generales que pueden ser aplicados en casi todos los procesos, tales como:

- Obtener o generar información objetiva necesaria, crear un clima de receptividad.

- Diagnosticar problemas y situaciones insatisfactorias, establecer un clima de confianza.
- Desarrollar potencialidades de colaboración entre los individuos y grupos, buscar nuevas fuentes de energía (física, mental y emocional).

- Compatibilizar armonizando e integrando las necesidades y los objetivos de la organización y de quienes forman parte de esta.

- Estimular la necesidad de establecer objetivos, metas y fines.

- Despertar la conciencia de establecer objetivos, metas y fines, buscar normas informales.

- Examinar el cómo, cuando, donde y cuanto de los valores y concepciones.

- Analizar las demandas, restricciones, oportunidades, cambios, desafíos del medio externo.

- Asociar la autoridad legal y el estatus funcional a las tres competencias: técnica, administrativa e interpersonal.

El desarrollo organizacional es un proceso de diagnóstico para mejorar la interacción de manera que aumente el desarrollo, dicho de otra forma, para lograr un cambio participativo, en el que se utilizan estrategias, métodos e instrumentos dentro de los sistemas abiertos, como son las organizaciones. Los sistemas están constituidos a su vez por subsistemas por lo que las intervenciones se pueden dar a nivel sistema organizacional, grupo o individuo, y se pueden calificar en (Augusto, 2007):

- Intervención en los procesos humanos.

- Intervenciones tecnoestructurales.

- Intervenciones en gestión de personas.

- Intervenciones estratégicas.

Los cambios son cualquier modificación de un estado a otro y es fácilmente perceptible dentro de un contexto, es llevado a cabo en función del desequilibrio para alcanzar homeostasis relativa y temporal, en el sistema organizacional. 
En general existen una serie de razones por las que exige planear los cambios:

- Hay cambios rápidos y radicales del entorno.

- Lograr durabilidad en los mismos.

- Que se aplique acorde con las necesidades de la organización.

- Aplicar estrategias y herramientas adecuadas.

- $\quad$ Logro de metas deseadas.

- Manejo de las resistencias al cambio.

- Alcanzar situación deseada con acciones prácticas adecuadas.

Es por lo anterior que se ha diseñado el proyecto de intervención con el objetivo de lograr el cuidado del medio ambiente del clúster de turismo alternativo para el desarrollo regional en la comunidad El Triunfo B.C.S., ubicada en la Micro Región Sur de La Paz B.C.S.

\section{Desarrollo sustentable y cuidado del medio ambiente}

Actualmente, la nueva modalidad del desarrollo llamada "Desarrollo sustentable" promueve la satisfacción de necesidades de los consumidores, pero sin comprometer el bienestar de las futuras generaciones. Es decir, hacer negocios, pero sin descuidar los impactos en económicos, sociales y ambientales. Lo cual obliga a tomar decisiones apropiadas a corto plazo con resultados a largo plazo.

La complejidad del desarrollo debe partir de aspectos esenciales como los fenómenos sociales y su naturaleza multidimensional; el proceso de desarrollo no puede entenderse plenamente si se consideran exclusivamente variables económicas, sin atender aspectos de carácter sociológico, cultural y político.
Se sabe que para construir una sociedad sustentable se necesita un desarrollo cuyo eje central sean las personas y se preocupe por el mejoramiento de la condición humana $\mathrm{y}$, además, esté basado en la conservación y mantenga la variedad y productividad de la naturaleza (Stor, 2001). La relación entre desarrollo sustentable de una comunidad y el territorio es importante porque permite mantener un equilibrio entre estos factores que explican cierto nivel de desarrollo del ser humano, el cual es transitorio, evoluciona y se puede traducir en una mejora en su calidad de vida (Dourojeanni, 2000).

El empoderamiento de las personas hacia su desarrollo social y económico es fundamental ya que tienen acceso, uso y control de recursos tanto físicos como ideológicos que los llevan a la participación de actividades relacionadas con su calidad de vida mediante un proceso donde se incrementa su capacidad de disponer sus propias vidas y su entorno.

Los problemas socioambientales crecen en gran medida por no lograr este equilibrio entre ser humano y ambiente, lo que ha implicado la elaboración de nuevas teorías, métodos y técnicas y su difusión a los actores académicos y organizaciones públicas y privadas, que garanticen la integridad ecológica del plantea y consideren fundamentos de justicia social, justicia productiva y justicia distributiva de un recurso $(\mathrm{R}, 1998)$.

El trabajo se ha desarrollado bajo el esquema del "Modelo del cambio planeado" de Faria de Mello, en la cual se presentan 2 fases, con 9 apartados en total que son: Contacto, Contrato, Entrada, Recolección de dato, Diagnóstico, Planeación de intervenciones, Acción, Institucionalización del cambio planeado, Acompañamiento y evaluación o retroalimentación. El alcance de la investigación que permite el desarrollo de las primeras seis etapas del modelo. Algunas de las ventajas de esta metodología son:

Capacidad de adaptabilidad y sensibilidad ante cambios de estímulos externos.

Presenta un proceso continuo.

Identificando y señalando pasos. 
Los objetivos de este trabajo es identicar actividades y procesos estratégicos, para el desarrollo de un plan de intervención integrado a la conformación del clúster de turismo alternativo en El Triunfo, municipio de La Paz Baja California Sur, que permita la reducción la pobreza y el aumento la calidad de vida en la región; sin comprometer el entorno natural. Integrando a los actores que conforman el sector de productos turísticos, generando entre ellos una visión compartida con el propósito de dar soluciones a los crecientes problemas de degradación del medio ambiente y conservación del entorno, identificando y analizando los elementos que deben fomentarse $\mathrm{y} / \mathrm{o}$ perfeccionarse para aumentar el desarrollo económico de la región.

\section{Antecedentes de la zona EI Triunfo}

En México, una de las actividades económicas más relevantes es el turismo. En Baja California Sur, desde la década de los setenta, Los Cabos y Loreto han colocado al estado como entidad concentrada en el turismo y como en el principal vector económico. Si bien esto ha traído grandes beneficios en materia de desarrollo económico, también ha traído como consecuencia el abandono de ciertas comunidades rurales con poca o nula actividad económico. Tal es el caso del Triunfo, es un antiguo pueblo minero que se ubica a 52 kilómetros de la ciudad de La Paz. Los yacimientos de oro y plata fueron las principales actividades económicas que originaron los asentamientos en esta región, en el siglo XIX.

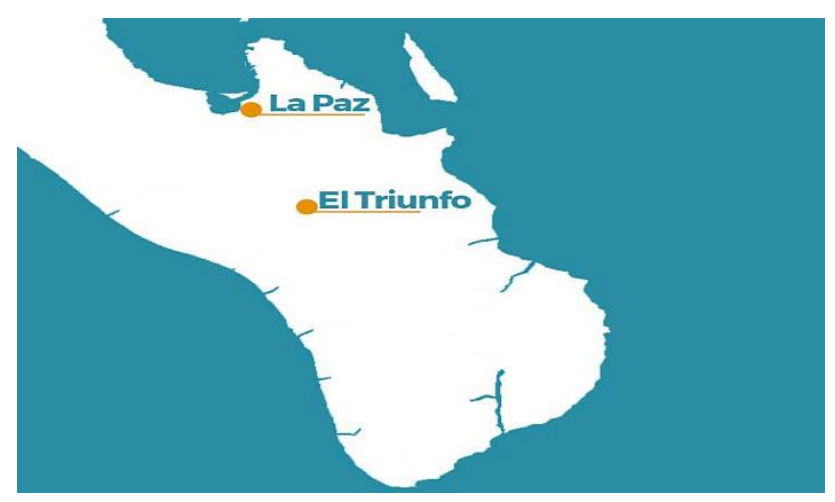

Figura 1 Ubicación geográfica de la localidad El Triunfo Fuente: Google.com

\section{Situación actual de la localidad El Triunfo, Baja California Sur}

A pesar de la riqueza cultural, natural y sus características geográfico-ambientales, esta localidad no han logrado desarrollar en tiempo reciente ninguno de sus potenciales. Por lo cual, desde hace algunos años, las tendencias muestran un decrecimiento en la población de esta comunidad actualmente cuenta con 463 habitantes y en apariencia que no se cuenta con una visión clara y compartida del futuro que se pudiera lograr.

La intervención está orientada al desarrollo sostenible, para abonar al entendimiento de la importancia que representa fortalecer las capacidades comunitarias que repercutan en el desarrollo integral, integrando el mejoramiento de la calidad de vida, pero dirigidos a cuidado del medio ambiente $\mathrm{y}$ propiciando la Conservación y desarrollo Sustentable para el Clúster identificado, como "una concentración geográfica de empresas de un ramo económico, de proveedores especializados de las mismas, de oferentes de servicios al productor, de compañías en ramas económicas vinculadas y de instituciones asociadas (gobiernos locales, universidades, centros de investigación, empresas certificadoras, asociaciones comerciales) que compiten y cooperan en un campo económico específico". (Porter, 1990, pág. 179) , a implementarse en la localidad.

Con el propósito de fomentar el desarrollo sostenible de esta localidad, es necesario crear estrategias para el mejoramiento social, económico y cultural de la calidad de vida de sus habitantes, a través del uso ecológicamente adecuado de los recursos, planeando los beneficios tanto para la generación presente como para futuras generaciones ( $R, 1998)$.

Para esta comunidad han prevalecido los estudios sobre la relevancia en temas de impacto ambiental en actividades como la extracción de minerales, siendo pocos los trabajos científicos que corroboren los impactos socioeconómicos de un desarrollo sustentable de un Clúster, en la comunidad, por lo que resulta de interés el presentar otras alternativas para el desarrollo de la región. 


\section{Método y desarrollo}

Tipo de investigación: descriptiva y de campo diseñaron:

En la que para su desarrollo se

Para la recopilación de la información se realizó un estudio socioeconómico aplicado a un total de 31 personas que fueron invitados previamente por el delegado por considerar que es de su interés participar con producción, se tomó en consideración en el estudio: ingreso económico, nivel de estudios, vivienda, servicios, cultura de ahorro entre otros.

Se llevó a cabo el procesamiento de la información Excel en graficas en donde se obtiene:

La mayor parte de la población manifiestan tener:

- Ingresos de entre 3000-6000 pesos mensuales.

- Estudios hasta nivel de primaria.

- Vivienda fabricada de concreto.

- Habitan en la vivienda de 1 a 3 miembros.

- Tienen servicios de energía eléctrica, agua y drenaje.

- Cuentan con sistemas de comunicación telefónica.

\section{- Cultura de ahorro.}

Con la intención de identificar las potencialidades, limitaciones y problemas, para hacer el diagnóstico referido a los recursos naturales y sociales disponibles y conocer la capacidad de desarrollo sustentable de la región, se diseñó una matriz de potencialidades que integra: aptitudes, capacidades y características especiales de la localidad para su desarrollo económico de manera sostenible.

Con esta matriz de potencialidades se abordaron aspectos de: área económica, sistema físico - natural, características orográficas de la región, demografía, con la finalidad de identificar en ellas oportunidades de mejora. (ver tabla 1).

\begin{tabular}{|c|c|c|}
\hline \multicolumn{3}{|c|}{$\begin{array}{c}\text { Matriz de potencialidades } \\
\text { Limitaciones } \\
\text { Área económica }\end{array}$} \\
\hline $\begin{array}{l}\text { Ecoturismo existente } \\
\text { Disposición a trabajar en } \\
\text { actividades sustentables } \\
\text { con uso de RN } \\
\text { renovables } \\
\text { Productos regionales } \\
\text { elaborados } \\
\text { artesanalmente }\end{array}$ & 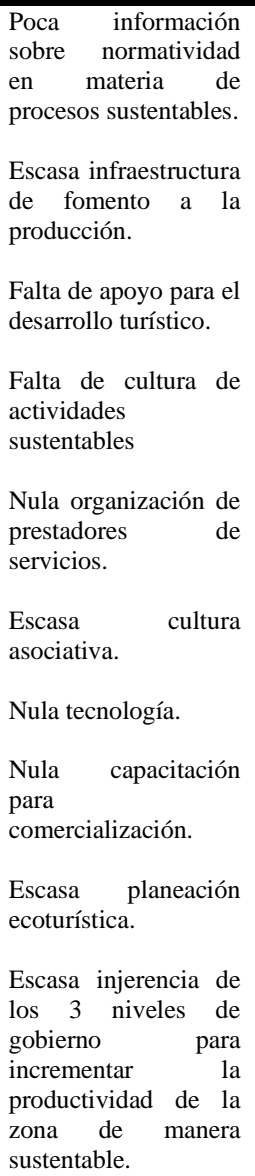 & $\begin{array}{l}\text { Los productos } \\
\text { regionales no se } \\
\text { comercializan de } \\
\text { manera organizada } \\
\text { y de forma } \\
\text { permanente. } \\
\text { Falta de difusión } \\
\text { de las actividades } \\
\text { ecoturísticas de la } \\
\text { zona. } \\
\text { Poca aceptación de } \\
\text { practicar } \\
\text { sustentabilidad en } \\
\text { los procesos. } \\
\text { El ecoturismo se } \\
\text { practica de manera } \\
\text { desorganizada y no } \\
\text { es incluyente con } \\
\text { toda la comunidad. }\end{array}$ \\
\hline Sistema físico - natur & Características orográ & icas de la Región \\
\hline $\begin{array}{l}\begin{array}{l}\text { Ubicación } \\
\text { para el }\end{array} \text { estratégica } \\
\text { ecoturínsito }\end{array}$ & $\begin{array}{l}\text { Disminución de la } \\
\text { afluencia de turistas } \\
\text { en verano, por las } \\
\text { altas temperaturas. }\end{array}$ & $\begin{array}{l}\text { En temporada de } \\
\text { ciclones, la } \\
\text { accesibilidad se ve } \\
\text { afectada }\end{array}$ \\
\hline & Demografía & \\
\hline $\begin{array}{l}\text { La población que tiene } \\
\text { actividad económica se } \\
\text { encuentra en el rango de } \\
\text { edad entre los } 38-67 \\
\text { años* }\end{array}$ & $\begin{array}{l}\text { Falta de interés por } \\
\text { los jóvenes de } \\
\text { mantenerse dentro de } \\
\text { la localidad ya que no } \\
\text { tienen buenos } \\
\text { incentivoseconómicos } \\
\text { y falta el trabajo } \\
\text { permanente. } \\
\text { Baja capacitación de } \\
\text { mano de obra para } \\
\text { sector terciario. } \\
\text { Bajo nivel educativo } \\
\text { de la población. } \\
\text {-Poco interés de los } \\
\text { productores en } \\
\text { capacitarse en materia } \\
\text { de sustentabilidad. }\end{array}$ & $\begin{array}{l}\text { Escasas } \\
\text { oportunidades de } \\
\text { empleo en la } \\
\text { localidad. } \\
\text { Bajos ingresos en } \\
\text { actividades } \\
\text { locales, por lo } \\
\text { tanto, emigración } \\
\text { en busca de } \\
\text { mejores } \\
\text { oportunidades. } \\
\text { Trabajos de } \\
\text { empleo temporal. }\end{array}$ \\
\hline
\end{tabular}

Tabla 1 Matriz de potencialidades 
Así mismo se diseñó una matriz de observación para identificar aspectos de: cultura asociativa, conocimiento de la normatividad y buenas prácticas en materia ambiental, falta de capacitación e infraestructura, tipo de organización en los prestadores de servicios, aceptación para apegar la sustentabilidad a sus procesos, entre otros.

En identificaron los aspectos legales que aplican en los aspectos de agua, atmosfera, suelo, uso eficiente de energía, flora y fauna, manejo y clasificación de residuos peligrosos en la cual se identifican los aspectos ambientales, seguido de la normatividad vigente aplicable a cada uno, tanto leyes federales, como estatales, municipales y reglamentos, con el fin de visualizar de manera más practica la normatividad con la que se tiene que cumplir según la actividad que desarrolle cada unidad de negocio.

Se diseño un instrumento de recolección de información, para diagnosticar el cumplimiento de la normatividad ambiental en las unidades negocio, con el objetivo de identificar qué aspectos ambientales se estaban afectando directamente.

El instrumento se diseñó de manera que fuera fácil identificar que aspecto ambiental se está impactando, así como que normatividad se está cumpliendo o incumpliendo según sea el caso, lo cual permitirá, visualizar de manera rápida como están operando las unidades de negocio actuales en materia ambiental.

\begin{tabular}{|c|c|c|c|c|}
\hline No. & $\begin{array}{c}\text { Fuente de } \\
\text { identificación/ } \\
\text { Aspecto }\end{array}$ & Ley Federal & $\begin{array}{c}\text { Ley } \\
\text { Estatal }\end{array}$ & $\begin{array}{c}\text { Ley } \\
\text { Municipal }\end{array}$ \\
\hline 1 & $\begin{array}{lr}\text { Extracción } & \text { y } \\
\text { consuma } & \text { de } \\
\text { agua } & \end{array}$ & $\begin{array}{l}\text { Reglamento De La } \\
\text { Ley General Del } \\
\text { Equilibrio Ecológico } \\
\text { y La Protección al } \\
\text { Ambiente (México, } \\
2020 \text { ) } \\
\text { En Materia De Áreas } \\
\text { Naturales Protegidas } \\
\text { (LGEEPA) } \\
\text { Reglamento De La } \\
\text { Ley De Aguas } \\
\text { Nacionales. (RLAN) } \\
\text { NOM-001- } \\
\text { SEMARNAT }\end{array}$ & $\begin{array}{l}\text { Ley De } \\
\text { Aguas Del } \\
\text { Estado De } \\
\text { B.C.S. } \\
\text { Ley De } \\
\text { Equilibrio } \\
\text { Ecológico } \\
\text { y } \\
\text { Protección } \\
\text { del } \\
\text { Ambiente } \\
\text { Del } \\
\text { Estado de } \\
\text { B.C.S. }\end{array}$ & $\begin{array}{l}\text { Ley } \\
\text { Orgánica } \\
\text { Municipal }\end{array}$ \\
\hline 2 & $\begin{array}{l}\text { Emisiones a la } \\
\text { atmósfera }\end{array}$ & $\begin{array}{lrr}\text { Ley Federal } & \text { de } \\
\text { Derechos en } & \text { las } \\
\text { Disposiciones } & \\
\text { aplicables en Materia } \\
\text { emisiones a la } \\
\text { Atmósfera. } \\
\text { Reglamento } \\
\text { LGEEPA }\end{array}$ & $\begin{array}{l}\text { Ley De } \\
\text { Equilibrio } \\
\text { Ecológico } \\
\text { y } \\
\text { Protección } \\
\text { del } \\
\text { Ambiente } \\
\text { Del } \\
\text { Estado de } \\
\text { B.C.S. }\end{array}$ & $\begin{array}{l}\text { Ley } \\
\text { Orgánica } \\
\text { Municipal }\end{array}$ \\
\hline 3 & Suelo & & & \\
\hline
\end{tabular}

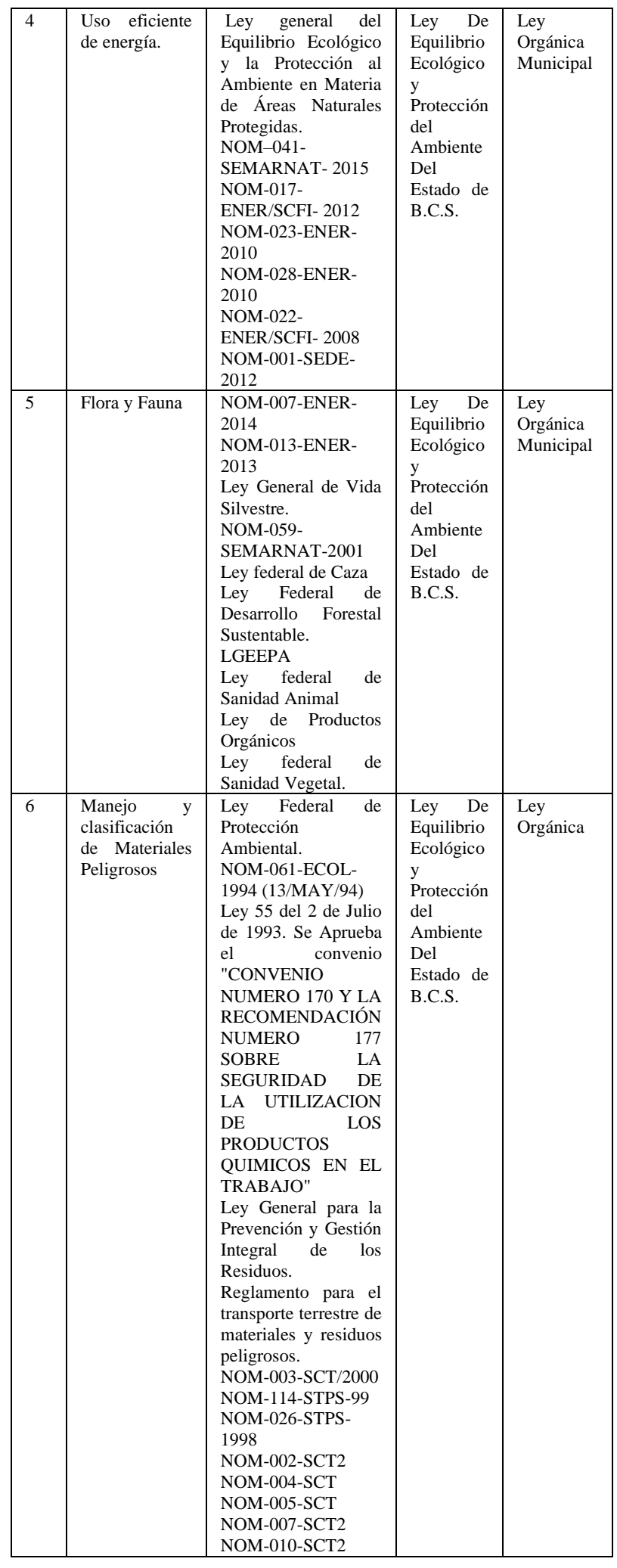

Tabla 2 Matriz de identificación de aspectos legales

Tomado en consideración las variables: aspectos ambientales, cumplimiento de la normatividad aplicable, potencialidades/ oportunidades se han determinado los riesgos en la matriz, en donde se obtiene: 
Junio 2020 Vol.6 No.18 1-9

\begin{tabular}{|c|c|c|c|}
\hline Aspecto & $\begin{array}{c}\text { Cumplimiento } \\
\text { de la } \\
\text { normatividad } \\
\text { aplicable }\end{array}$ & Potencialidades & $\begin{array}{l}\text { Identificación de } \\
\text { riesgos }\end{array}$ \\
\hline Agua & $\begin{array}{l}\text { Nacional } \\
\text { Estatal } \\
\text { Municipal }\end{array}$ & $\begin{array}{ll}\text {-Ecoturismo } \\
\text { existente } \\
\text {-Disposición } \\
\text { trabajar } \\
\text { actividades } \\
\text { sustentables } \\
\text { uso de con } \\
\text { RN }\end{array}$ & $\begin{array}{l}\text {-Desperdicio por } \\
\text { fugas } \\
\text {-Malas practicas } \\
\text {-Contaminación } \\
\text { por vertido de } \\
\text { desechos tóxicos }\end{array}$ \\
\hline Atmosfera & & $\begin{array}{l}\text { renovables } \\
\text {-Productos }\end{array}$ & $\begin{array}{l}\text {-Emisión de humos } \\
\text { de fuentes } \\
\text { contaminantes }\end{array}$ \\
\hline Suelo & & $\begin{array}{l}\text { regionales } \\
\text { elaborados } \\
\text { artesanalmente }\end{array}$ & $\begin{array}{l}\text {-Vertido de residuos } \\
\text { sólidos urbanos y de } \\
\text { manejo especial. }\end{array}$ \\
\hline Energía & & $\begin{array}{l}\text {-Ubicación } \\
\text { estratégica para el } \\
\text { tránsito } \\
\text { ecoturístico. }\end{array}$ & $\begin{array}{l}\text {-Instalaciones } \\
\text { eléctricas } \\
\text { inadecuadas } \\
\text {-Malas practicas }\end{array}$ \\
\hline $\begin{array}{l}\text { Flora } \quad y \\
\text { fauna }\end{array}$ & & $\begin{array}{l}\text {-Ubicación } \\
\text { cercana a la } \\
\text { ciudad de La Paz } \\
\text { que facilita la } \\
\text { afluencia de }\end{array}$ & $\begin{array}{l}\text {-Desconocimiento } \\
\text { de las especies } \\
\text { protegidas ubicadas } \\
\text { en el la zona y su } \\
\text { tratamiento para } \\
\text { protección. }\end{array}$ \\
\hline $\begin{array}{l}\text { Residuos } \\
\text { peligrosos }\end{array}$ & & $\begin{array}{l}\text { turistas locales y } \\
\text { extranjeros. } \\
\text {-Recurso de agua } \\
\text { disponible para } \\
\text { cualquier } \\
\text { actividad } \\
\text {-La población que } \\
\text { tiene actividad } \\
\text { económica se } \\
\text { encuentra en el } \\
\text { rango de edad } \\
\text { entre los 38-67 } \\
\text { años }\end{array}$ & $\begin{array}{ll}\text {-Generación } & \text { de } \\
\text { aceite quemado } & \text { en } \\
\text { producción } & \text { de } \\
\text { alimentos. } & \end{array}$ \\
\hline
\end{tabular}

Tabla 3 Matriz de Identificación de riesgos

Se identifican los riesgos en la matriz y se determinan como oportunidades para la prevención y mitigación de los posibles impactos a tomar en consideración para la propuesta.

\section{Resultados}

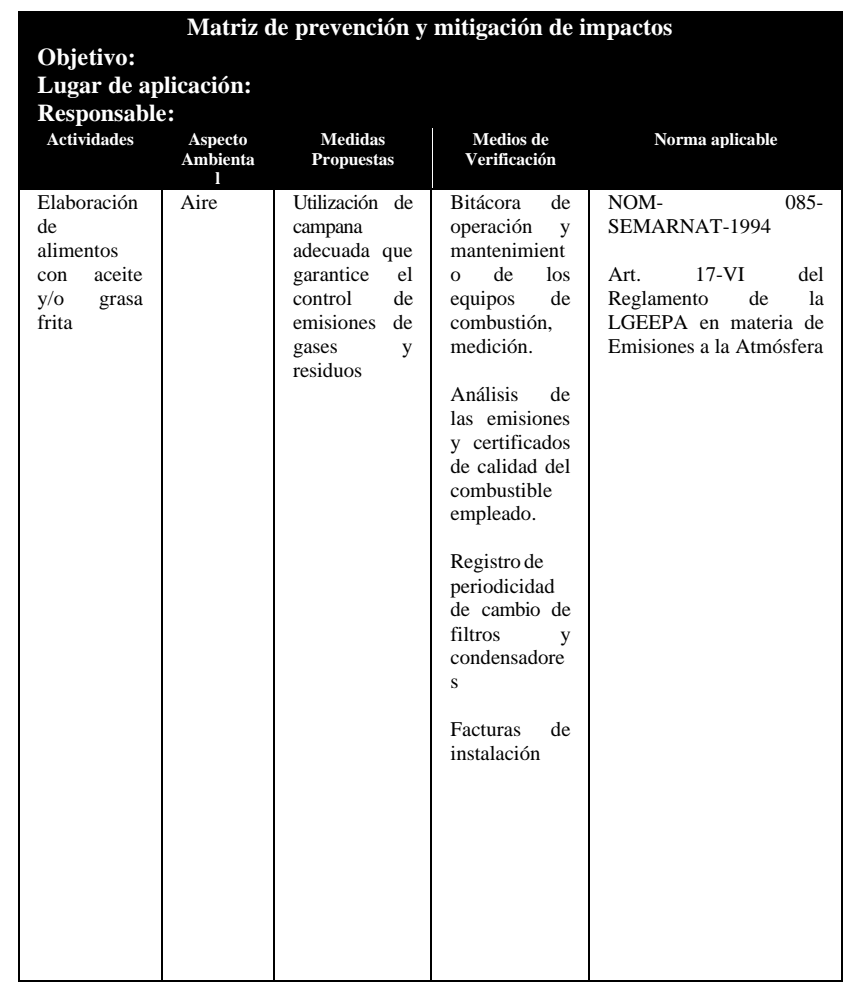

\begin{tabular}{|c|c|c|c|c|}
\hline $\begin{array}{l}\text { Uso de } \\
\text { vehículos de } \\
\text { transporte }\end{array}$ & Aire & $\begin{array}{l}\text { Bitácora de } \\
\text { manteamiento } \\
\text { necesario que } \\
\text { garanticen el } \\
\text { control de las } \\
\text { emisiones de } \\
\text { gases } \\
\text { provenientes } \\
\text { de le la } \\
\text { combustión } \\
\text { del motor. }\end{array}$ & $\begin{array}{l}\text {-Registro en } \\
\text { Bitácora de } \\
\text { operación y } \\
\text { mantenimient } \\
\text { o de los } \\
\text { equipos de } \\
\text { transporte. } \\
\text { Medición y } \\
\text { análisis de las } \\
\text { emisiones. } \\
\text {-Certificados } \\
\text { de calidad del } \\
\text { combustible } \\
\text { empleado. } \\
\text {-Registrode } \\
\text { periodicidad } \\
\text { de cambio de } \\
\text { filtros y y } \\
\text { condensadore } \\
\text { s } \\
\text { Facturas de } \\
\text { instalación. }\end{array}$ & $\begin{array}{l}\text { NOM } \\
\text { SEMARNAT-2006 }\end{array}$ \\
\hline $\begin{array}{l}\text { Uso fogatas } \\
\text { para } \\
\text { residuos }\end{array}$ & Aire & & & $\begin{array}{l}\text { NOM-015- } \\
\text { SEMARNAT/SAGARP } \\
\text { A-2007 } \\
\text { Art. } 27 \text { del Reglamento } \\
\text { de la LGEEPA en } \\
\text { materia de Emisiones a la } \\
\text { Atmósfera }\end{array}$ \\
\hline $\begin{array}{l}\text { Generación } \\
\text { de aceites y y } \\
\text { grasas, } \\
\text { tensocactivos } \\
\text { y yefluentes } \\
\text { residuales }\end{array}$ & Suelo & $\begin{array}{l}\text { Utilización de } \\
\text { trampas } \\
\text { propias } \\
\text {-Utilización } \\
\text { de bitácoras } \\
\text { de } \\
\text { mantenimient } \\
\text { o preventivo } \\
\text { y correctivo. } \\
\text { Procedimient } \\
\text { Prepara el } \\
\text { o pant de la } \\
\text { control desición de } \\
\text { dispes residuos } \\
\text { los } \\
\text { de removidos } \\
\text { de las trampas } \\
\text {-Contrato con } \\
\text { empresa } \\
\text { certificada } \\
\text { para } \\
\text { disposición de } \\
\text { los residuos. } \\
\text {-Licencia } \\
\text { ambiental } \\
\text { vigente. }\end{array}$ & $\begin{array}{l}\text {-Bitácora de } \\
\text { tratamiento y } \\
\text { recopilación } \\
\text { de residos - } \\
\text { Bitácora de } \\
\text { entrega a } \\
\text { gestor a } \\
\text { autorizado } \\
\text {-Informe de } \\
\text { tratamiento } \\
\text { final que el } \\
\text { gestor da a los } \\
\text { desechos } \\
\text { entregados. } \\
\text {-Registro } \\
\text { fotografico }\end{array}$ & 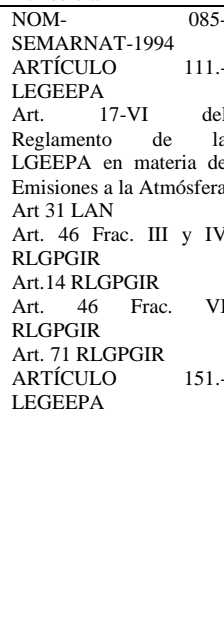 \\
\hline $\begin{array}{l}\text { Desechos } \\
\text { Solidos }\end{array}$ & Suelo & $\begin{array}{l}\text { Clasificar } \\
\text { disponer de } \\
\text { los Residuos } \\
\text { Sólidos } \\
\text { Urbanos } \\
\text { conforme a lo } \\
\text { establecido en } \\
\text { la Ley. } \\
\text { Utilización de } \\
\text { métodos } \\
\text { como Cinco } \\
\text { Erres } \\
\text { (reutilizar, } \\
\text { reducir, } \\
\text { reparar, } \\
\text { reciclar y } \\
\text { rechazar y }\end{array}$ & $\begin{array}{l}\text {-Bitácora de } \\
\text { recepción } \\
\text { de material } \\
\text { susceptible } \\
\text { de ser } \\
\text { reciclado } \\
\text { en los } \\
\text { centros de } \\
\text { acopio } \\
\text { integrales } \\
\text { universitari } \\
\text { os. } \\
\text {-Bitácora de } \\
\text { disposición } \\
\text { final de } \\
\text { residuos } \\
\text { sólidos } \\
\text {-Manifiestos } \\
\text { SEMARN } \\
\text { AT de } \\
\text { Aisposición } \\
\text { de residoos } \\
\text { de manejo } \\
\text { especiala }\end{array}$ & $\begin{array}{l}\text { LEGEEPA } \\
\text { Reglamento federal de } \\
\text { seguridad e higiene uy } \\
\text { medio ambiente de } \\
\text { trabajo (RFSHMAT) } \\
\text { Ley General para la a } \\
\text { Prevención y Gestión } \\
\text { Integral de los Residuos } \\
\text { (D.O.F. 3-X2003) } \\
\text { reforma 19-06-2007 } \\
\text { Ley de la gestión de los } \\
\text { desechos sólidos } \\
\text { humanos. }\end{array}$ \\
\hline
\end{tabular}

Tabla 4 Matriz de prevención y mitigación de impactos

Se ha considerado en este seguimiento y análisis la definición de acciones estratégicas para la intervención para una vez que sea conformado el clúster una de sus principales filosofías se refiera al cuidado y preservación del medio ambiente. 


\begin{tabular}{|c|c|c|}
\hline $\begin{array}{c}\text { Acciones } \\
\text { estratégicas }\end{array}$ & Método & $\begin{array}{c}\text { Indicadores / } \\
\text { evidencias }\end{array}$ \\
\hline $\begin{array}{l}\text { Reuniones de } \\
\text { información y } \\
\text { trabajo con los } \\
\text { interesados. }\end{array}$ & 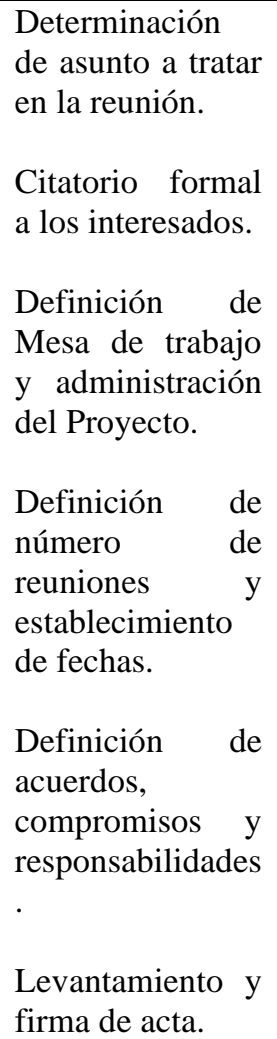 & $\begin{array}{l}100 \% \text { de los } \\
\text { interesados que } \\
\text { acuden a reunión/ } \\
\text { lista de asistencia } \\
100 \% \\
\text { cumplimento de } \\
\text { responsabilidades } \\
\text { / informe de } \\
\text { resultados }\end{array}$ \\
\hline $\begin{array}{l}\text { Plan de } \\
\text { capacitación }\end{array}$ & 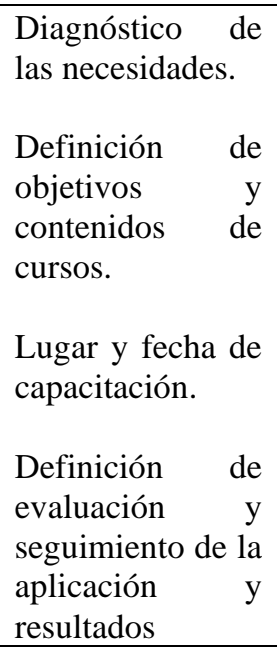 & 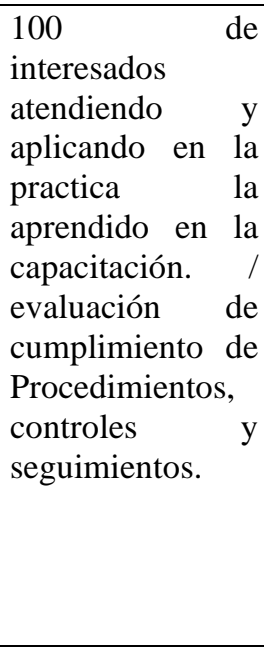 \\
\hline $\begin{array}{l}\text { Diseño y } \\
\text { aplicación de } \\
\text { procedimientos } \\
\text { formatos, } \\
\text { bitácoras, } \\
\text { controles y } \\
\text { documentación } \\
\text { propia para el } \\
\text { proyecto. }\end{array}$ & $\begin{array}{l}\text { En reuniones de } \\
\text { trabajo por } \\
\text { método de } \\
\text { Coaching generar } \\
\text { los documentos, } \\
\text { evaluación de su } \\
\text { funcionalidad y } \\
\text { de ser el caso } \\
\text { reestructurar. }\end{array}$ & $\begin{array}{l}100 \quad \text { de } \\
\text { evidencias } \\
\text { presentadas. }\end{array}$ \\
\hline
\end{tabular}

Tabla 5 Acciones estratégica para llevar a cabo la intervención en el cuidado del medio ambiente en la integración de clúster de turismo alternativo en el Triunfo B.C.S.

\section{Conclusión}

Con el propósito de mitigar y prevenir los riesgos ambientales que se pudieran generar por las actividades de las unidades de negocio que conforman la cadena de valor, se ha diseñado una matriz de Prevención ambiental, en la cual se señalan las actividades que deben darse durante la implementación en el proceso de intervención durante la puesta en marcha del clúster de turismo alternativo para incentivar la formación de la cultura del cuidado del medio ambiente en la localidad desde el nacimiento del clúster de turismo alternativo, y evitar los impactos negativos que se pudieran presentar en lo futuro como resultado de la participación de los habitantes de la localidad al generar su propia fuente de empleo e incidir en la permanencia en su lugar de origen.

La formación de la cultura en el cuidado del aspecto ambiental en la localidad es relevante dado que es importante la conservación, por lo que es relevante el diseño de acciones estratégicas y el cumplimiento de los compromisos de se adquieran para su logro, que si bien en la actualidad no hay muestras de impactos visibles, y se sabe que durante la extracción de minerales en esa región si hubo generación de residuos, pero es importante que en lo futuro se conserve sin afectaciones por lo que la utilización de la normatividad dispuesta por las leyes aplicables posibilita su implementación. Todo esto con el objetivo de prevenir, mitigar, corregir o compensar los impactos y efectos ambientales que se causen por el desarrollo de la actividad turística en la localidad de El Triunfo, Baja California Sur.

\section{Agradecimiento}

Este proyecto ha sido financiado por Tecnólogo Nacional de México, al cual agradecemos infinitamente los apoyos que a través de Instituto Tecnológico de la $\mathrm{Paz}$ al que orgullosamente pertenecemos, el objetivo ha sido el diseño de propuesta para la intervención y lograr el cuidado del medio ambiente en la integración del clúster de turismo alternativo para el desarrollo regional tomando como caso de estudio la comunidad El Triunfo, ubicada en la Micro Región Sur de La Paz B.C.S. y por medio del Cuerpo Académico "Gestión de Procesos Organizacionales" se ha autorizado este proyecto. 


\section{Referencias}

Audirac Camarena Carlos A., D. L. (2014). $\mathrm{ABC}$ del desarrollo Organizacional. México: Trillas.

Augusto, A. C. (2007). Desarrollo Orgtanzacionql y cosultoría. México: Trillas.

Dourojeanni, A. (2000). Procedimientos de gestión para el desarrollo sustentable. chilr.

México, G. d. (2020). Ley General Del Equilibrio Ecológico y $\mathrm{La}$ Protección al Ambiente . México: Gobierno de México.

Porter. (1990). La competitividad de las Naciones. Harvad Bussines.

R, G. (1998). Aterrizando una cometa: indicadores territoriales de sustentabilidad.

Stor. (2001).

Bogabir,

$\mathrm{X}$.

(2006).

https://www.guioteca.com/rse/empresas-

sustentables-como-entenderlas/.

Carpi, J. A. (2008). El desarrollo local sostenible en clave estratégica. El desarrollo local sostenible en clave estratégica.

Chervel, M., \& Gall, M. L. (1991). Manual de evaluación económica de proyectos: el método de los efectos.

Coronel, T. I. (1972). Algunos comentarios sobre aspectos metodológicos en la formación de proyectos.

Frederick,

$P$.

https://www.guioteca.com/rse/empresas-

(2006). sustentables-como-entenderlas/.

Gobierno, S. d. (2017). http://www.conabio.gob.mx/uicn/SEMARNAT CONANP.html.

J, J. U. (1995). Energía y Medio Ambiente una perspectiva económica social. México: UNAM.

Juste, I. (2018). https://educacion.uncomo.com/articulo/cual-esla-diferencia-entre-sustentable-y-sostenibleconocela-aqui-21657.html.
Liera, I. S. (noviembre de 2003). Metodología para la elaboración de Estrategias de Desarrollo Local.

Obtenido

de file://C:/Users/52612/Downloads/Ivan_Silva_L ira_Metodologia_para_la_Elab.pdf.

MÉXICO, G. D. (s.f.). https://www.gob.mx/profepa/que-hacemos. 